\title{
INTERDISCIPLINARIDADE E TRANSDISCIPLINARIDADE COMO FUNDAMENTOS NA AÇÃO PEDAGÓGICA: APROXIMAÇÕES TEÓRICO-CONCEITUAIS
}

Juliane Gomes de Sousa ${ }^{1}$

Maria José de Pinho $^{2}$

\begin{abstract}
Resumo: O presente texto tem por objetivo discutir teoricamente acerca da interdisciplinaridade e da transdisciplinaridade como alternativas para a efetivação das açôes pedagógicas no contexto educacional da contemporaneidade. As reflexóes desencadeadas constituem-se como recorte da fundamentação teórica da dissertação de Mestrado em Educação da Universidade Federal do Tocantins. O estudo tem como foco o debate em torno da interdisciplinaridade e da transdisciplinaridade como potenciais de mudanças na atualidade, valendo-se da prerrogativa de que é vivenciado um contexto marcado por intensas transformaçóes e que exigem o (re) pensar, (re) construir e encaminhar a ação pedagógica a partir de um olhar sistêmico e da integração dos seus elementos constituintes. Frente às discussóes desenvolvidas, pontua-se que a ação pedagógica alicerçada na abordagem intertransdisciplinar é caracterizada por uma visão de dialogicidade, abertura, integração, valorização da diversidade, da escuta sensível, parcerias e cooperação. Esses elementos são tidos como potenciais para o desencadeamento de práticas e atitudes criativas no cenário educativo.
\end{abstract}

Palavras-chave: Interdisciplinaridade. Transdisciplinaridade. Ação pedagógica.

\section{INTERDISCIPLINARITY AND TRANSDISCIPLINARITY AS FOUNDATIONS IN PEDAGOGICAL ACTION: THEORETICAL- CONCEPTUAL APPROACHES}

Asbtract: The present text aims to discuss theoretically about interdisciplinarity and transdisciplinarity as alternatives for the effectiveness of pedagogical actions in the contemporary educational context. As reflections unchained constitute a cut of the theoretical basis of the master's dissertation in Education

1 Graduada em Pedagogia (UFT). Mestre em Educação (PPGE/UFT). Professora da Educação Básica.

2 Doutora em Educação e Currículo pela PUC/SP. Docente nos Programas de Pós-Graduação: Mestrado/Doutorado - Letras, Ensino de Língua e Literatura; Mestrado em Educação da Universidade Federal do Tocantins (UFT). 
of the Federal University of Tocantins. The study focuses on the debate around interdisciplinarity and transdisciplinarity as potential changes in the present time, using the prerogative of experiencing a context marked by intense transformations and requiring (re) thinking, (re) build and forward a pedagogical action based on a systemic view and integration of its constituent elements. Faced with the discussions, it is pointed out that the pedagogical action based on the inter-transdisciplinary approach is characterized by a vision of dialogue, openness, integration, appreciation of diversity, sensitive listening, partnerships, community. Elements, these, considered as potential for the triggering of practices and creative attitudes without educational scenario.

Keywords: Interdisciplinarity. Transdisciplinarity. Pedagogical action.

\section{INTRODUÇÃO}

Os arranjos no âmbito educacional têm sido fortemente constituídos sob o prisma do paradigma da modernidade, o que tem caracterizado a assunção de modelos pedagógicos cuja centralidade se pauta na compartimentalização, na fragmentação do conhecimento e em uma racionalidade excludente, a qual apregoa a marginalização do sujeito em sua multidimensionalidade, assim como a diversidade de saberes existentes no contexto vivencial.

Diante desse cenário, a emergência de epistemologias que referenciam o mundo fenomênico a partir de uma lógica complexa provocou o questionamento da visão sectária predominante nos diferentes arranjos e dimensões da sociedade, acarretando a constatação do seu esgotamento para as explicações, frente às mutações contemporâneas.

É nesse escopo que urge a necessidade de (re) pensar os aspectos educacionais, tais como a ação pedagógica, pautando-os em outras estruturas perceptivas, amparados em “[...] uma visão sistêmica e transdisciplinar, o que significa substituir compartimentalização por integração, desarticulação por articulação" (TRONCA, 2006, p. 81). Assim, a interdisciplinaridade e a transdisciplinaridade são abordagens epistemológicas que coadunam com essa busca pelo olhar que conecta, integra e estabelece o diálogo permanente.

Nessas circunstâncias, os fundamentos epistemológicos, ontológicos e metodológicos da interdisciplinaridade e da transdisciplinaridade vêm se constituindo como possibilidade de mudanças nas ações e nas práticas pedagógicas desenvolvidas no âmbito formativo, as quais, tendo por base esse referencial, podem deixar de ser mecânicas e reprodutivas, para serem pensadas e repensadas como uma construção complexa e que possam envolver "[...] diferentes áreas do conhecimento [...] um olhar mais amplo e abrangente sobre as situações que aflora no contexto [...]" (PEREIRA, F; PINHO, 2015, p.51) educativo. De tal modo, as ações pedagógicas são visualizadas como fatores essenciais para o desenvolvimento de novos conhecimentos, de novas competências pessoais e profissionais, e das relações intersubjetivas.

A partir disso, o presente artigo objetiva discutir teoricamente acerca $\mathrm{da}$ interdisciplinaridade e da transdisciplinaridade como alternativas para a efetivação das ações pedagógicas no contexto educacional da contemporaneidade, 
pretendendo desencadear uma reflexão que perpasse pela proposição da formação fundamentada em outros referenciais, os quais se desvelem mais coerentes em dar respostas às demandas oriundas das transformações ocorridas no contexto social e, porquanto, no âmbito educacional contemporâneo.

Para o desencadeamento dessas discussões, o caminho metodológico percorrido se sustenta na análise do conteúdo de uma pesquisa bibliográfica, enfatizando a fundamentação epistemo-metodológica que caracteriza a interdisciplinaridade e a transdisciplinaridade na ação pedagógica, a partir da qual se buscou recorrer aos pressupostos teóricos de diferentes autores como forma de sustentar e subsidiar a reflexão pretendida.

Sendo assim, esta composição escrita se organiza a partir de três seções e suas respectivas subdivisões: Aproximações conceituais; interdisciplinaridade; transdisciplinaridade, na qual se busca pela fundamentação conceitual dessas duas bases epistêmicas; Prática e ação pedagógica Inter/Transdisciplinares: um caminho possível, nesta se recorre à integração da discussão entre os fundamentos teórico-metodológicos e a ação pedagógica docente; e são, ainda, pontuadas algumas considerações finais, em que são tecidas reflexões gerais referentes à temática apresentada.

\section{APROXIMAÇÓES CONCEITUAIS}

Empreender uma discussão acerca da ação pedagógica amparada nos fundamentos da interdisciplinaridade e da transdisciplinaridade preside a elucidação de alguns dos seus aspectos, tais como: etimologia, surgimento, conceituação e características gerais. Com esse intuito, pretende-se, inicialmente, fazer uma breve contextualização, ressaltando o fato de que, diante da proposição de abertura, diálogo e integração, que emergem como cerne de suas configurações, estas interdisciplinaridade e transdisciplinaridade - se apresentam como aportes teóricoepistemológicos com exponencial poder de mudança, ressignificação e reconstrução dos modelos vivenciados no âmbito formativo da contemporaneidade.

\subsection{INTERDISCIPLINARIDADE}

Compreender a interdisciplinaridade requer entender suas origens e características, perpassando pelo contexto em que é referenciada como atitude que visa entrelaçar os diferentes conhecimentos disciplinares. Portanto, cabe situar que a palavra interdisciplinaridade é composta pela conjunção do prefixo "[...] inter que significa ação recíproca, e [...] disciplinar - termo que diz respeito à disciplina, [...]" (AIUB, 2006, p. 107, grifos da autora), referindo-se, assim, à ação pela qual se efetua o esforço "[...] para correlacionar disciplinas, descobrir uma axiomática comum entre elas" (MORAES, 1997, p. 182), no intuito de proporcionar um aprendizado consubstanciado, concomitantemente, por diferentes saberes.

$\mathrm{Na}$ esteira histórica, o debate em torno da interdisciplinaridade tem origem na Grécia Antiga, Fazenda (2003); e naquele contexto, perpassava pela premissa de 
que a formação do modelo ideal de homem deveria contemplar diversos saberes, caracterizando uma formação integral.

Contudo, essa proposta de formação e de conciliação entre as áreas das ciências, concebida pelo homem grego, foi sendo interrompida gradativamente pela crescente lógica de separação e emergência de dualidades no mundo ocidental, tais como: corpo/alma, natureza/sujeito, razão/emoção, as quais ganham força pela presença e crescimento vertiginoso do pensamento disjuntivo, enaltecido na Revolução Científica (século XVI). Neste contexto, entre outras formulações, ratificou-se a visão do parcelamento da realidade, dos conhecimentos, do homem e da natureza em partes isoladas para seu estudo e compreensão, fundamentando, assim, toda a base de pensamento que caracteriza o paradigma da modernidade.

Com isso, a configuração da pedra angular do edifício intelectual (MORIN, 2007) da modernidade se estabeleceu na máxima de que,

[...] quando um fenômeno é complexo, deve-se descontextualizar, desmembrar, simplificar, classificar, reduzir. [...] Descartes, dissocia sociedade/natureza, sujeito/objeto, razão/emoção, ser/saber e valoriza um dos polos: da razão, da racionalidade, do objeto, da objetividade, do saber; em detrimento do sujeito, da emoção, da sensibilidade, da subjetividade e da espiritualidade (SANTOS A., et al., 2014, p. 79).

Nesse pensar, prevalece o caráter dual, cuja característica marcante é a polarização binária e a racionalidade objetiva. De tal modo, ocorre a anulação dos aspectos subjetivos, que também constituem o sujeito, sobressaindo o viés da neutralidade e da objetividade, ou seja, a razão nos modos de conhecer e perceber a realidade que é desvelada.

Com o desenvolvimento das ciências e do questionamento à vertente da fragmentação - sobretudo pelas descobertas no âmbito da física, tendo como destaque a revolução causada pelas descobertas da mecânica e, posteriormente, da física quântica - as discussões acerca das limitações da forma de parcelamento do conhecimento começam a compor o debate no meio científico, irrompendo no reaparecimento da necessidade indispensável da busca por alternativas que estabeleçam "[...] os laços entre as diferentes disciplinas [...]" (NICOLESCU, 1999, p. 50). Nesse cenário, a interdisciplinaridade e, de forma mais abrangente, a transdisciplinaridade surgem como resposta à procura por um conhecimento mais integrado, articulado e complexificado.

Sob essa ótica, “a interdisciplinaridade, como questão gnosiológica, surgiu [...] pela necessidade de dar resposta à fragmentação causada por uma epistemologia de cunho positivista" (GADOTTI, 1999, p. 01, grifo do autor), configurando, deste modo, a busca pela articulação entre as áreas das ciências, como proposta para o estabelecimento do diálogo entre elas. Seu desenvolvimento se efetivou em diversas dimensões.

No que concerne ao campo conceitual, não há consenso sobre o termo interdisciplinaridade, verificando-se, pela bibliografia consultada, uma multiplicidade em torno do seu conceito, constatação que vai ao encontro do que assinala Gadotti 
(1999, p. 05), quando externaliza que "o conceito de interdisciplinaridade não é unívoco. Ele [...] está sujeito ao conflito de interpretações".

Assim, nesse contexto polissêmico e fluído das definições de interdisciplinaridade, destaca-se a conceituação proposta por Nicolescu (1999, p.50): "A interdisciplinaridade [...] diz respeito à transferência de métodos de uma disciplina para outra", a qual, segundo o autor, pode ser verificada a partir de três graus: a) um grau de aplicação; b) um grau epistemológico; c) um grau de geração de novas disciplinas. Essa acepção se inclina para o desdobramento da interdisciplinaridade dentro do âmbito metodológico, vista como produtora de novas configurações e geradora de outros campos do conhecimento.

Por outro lado, em uma concepção que transcende a lógica de transferência para uma ideia de colaboração, ressalta-se a definição apresentada por Suanno, M., (2015, p. 109, grifo nosso) a qual a assinala como "coordenação, cooperação e integração entre disciplinas, suas especificidades e seus domínios linguísticos, [...] que demanda diálogo, abertura e atitude colaborativa dos sujeitos no ato de investigar e conhecer juntos". Projetando, assim, a necessidade de atitude, do querer desenvolver-se em parceria, para a construção de um projeto coletivo que se faz a partir de trocas recíprocas e de modo recorrente.

Nesse movimento, segundo Fazenda (2003), para que a interdisciplinaridade se efetive como atitude, é necessário o rompimento das barreiras disciplinares. É, em outras palavras, transgredir as grades das gaiolas epistemológicas (D'Ambrosio - informação verbal ${ }^{3}$ ), permitindo a aventura de ir além das limitações consensualmente impostas. Assumindo essa lógica, torna-se imprescindível uma decisão pessoal mediada por uma postura de abertura e flexibilidade, que permita um diálogo permanente, propiciador de um envolvimento constante, como premissa constituinte da interconectividade entre saberes e das trocas disciplinares.

Dessa forma, postula-se que, circunscrita em uma nova estrutura de pensamento, a interdisciplinaridade "[...] auxilia no transcorrer das mudanças aumentando o poder dialógico, integrando o compartilhar de saberes [...]" (ANJOS, 2015, p.38) balizando, com isso, o ressignificar de ações rumo a uma postura de abertura epistemológica e metodológica, que, por consequência, resulta em práticas ancoradas no potencial de transformação.

\subsection{TRANSDISCIPLINARIDADE}

A transdisciplinaridade favorece um diálogo vivo, promotor de uma abertura que visa à conjunção. Assim, consolida-se como campo fértil na articulação entre os diferentes níveis de organização do conhecimento (disciplinaridade, multidisciplinaridade, pluridisciplinaridade, interdisciplinaridade), e em uma postura de transcendência, amplia-se para além deles.

3 Concepção discutida por Ubiratan D'Ambrosio durante a Conferência Internacional saberes para uma cidadania planetária, realizada em Fortaleza, em maio de 2016. 
Desse modo, em uma tentativa de conceituação, sendo válido ressaltar que essa tentativa constitui apenas "[...] um certo esforço semântico para conceitualizar algo que [...] escapa por sua própria natureza, a toda e qualquer definição e esquematização" (MORAES, 2015b, p. 90), apresenta-se a definição proposta por Nicolescu (1999, p.50, grifos do autor), o qual designa: "A transdisciplinaridade, como o prefixo 'trans' indica, diz respeito àquilo que está ao mesmo tempo entre as disciplinas, através das diferentes disciplinas e além de qualquer disciplina [...]". Concepção que acentua seu caráter multidimensional, baseando-se em uma atitude que transborda o campo das disciplinas, buscando a complexidade dos saberes. É uma abordagem que visa à validação dos conhecimentos tidos como "não científicos", rejeitados pelas normas paradigmáticas da ciência moderna, dentre os quais é possível indicar: a arte, a filosofia e as tradições de sabedoria (SOMMERMAN, 2006).

$\mathrm{O}$ contexto de surgimento da transdisciplinaridade situa-se em meio às tensões provocadas pelos questionamentos das certezas e das verdades absolutas projetadas pelo "[...] racionalismo, do século XVII ao século XIX, e o empirismo, do século XIX até hoje" (SOMMERMAN, 2006, p.14), os quais constituem a força motriz da configuração da lógica do conhecimento fragmentado, retalhado em meio ao campo da especialização e até mesmo da hiperespecialização (metade do século XX).

Com isso, os abalos suscitados no âmbito da lógica paradigmática dominante proporcionaram a (re) construção de uma perspectiva epistemológica, cosmológica e antropológica que se sustenta numa visão multidimensional. Sendo nesse escopo de efervescência por bases que contemplam o conhecimento, o universo e o homem em sua totalidade, que a transdisciplinaridade emerge, apoiando-se na busca pela unidade aberta, complexa.

Com efeito, Nicolescu (1999, p.09) assim assinala o surgimento do termo transdisciplinaridade:

Tendo surgido, há três décadas, quase simultaneamente, nos trabalhos de pesquisadores diferentes como Jean Piaget, Edgar Morin, Eric Jantsch e muitos outros, este termo foi inventado na época para traduzir a necessidade de uma jubilosa transgressão das fronteiras entre as disciplinas, sobretudo no campo do ensino e de ir além da pluri e da interdisciplinaridade.

Inaugura-se, pois, no campo conceitual, a definição de uma perspectiva revolucionária que representou um novo horizonte para o pensamento ocidental, assentando-se no irrestrito, na possibilidade de ir e vir entre as diversas abordagens, no caráter complementar do conhecimento que se manifesta interconectado no universo sensível e inteligível.

Nesta direção, a transdisciplinaridade, em uma dimensão ontológica, projeta o homem como um ente reconciliado com a natureza, o mundo e a vida. Questionando os fundamentos do paradigma dominante (SANTOS B., 2001), que referencia o sujeito a partir do caráter disjuntivo, fragmentado, dicotomizado, essa base visa conceber e instituir um ser indiviso, dotado de dimensões complementares, mente/ 
corpo, razão/emoção, material/espiritual, indivíduo/natureza, o qual se constitui em meio a uma relação complexa a partir de uma realidade que é multidimensional e multirreferencial.

De igual modo, do ponto de vista da epistemologia, a transdisciplinaridade guia-se por "[...] um pensar que, ao invés de valorizar a simplificação, valoriza a complexidade, a tessitura articulada dos saberes e dos conhecimentos [...]" (SUANNO, M., 2015, p.88), propondo a valorização e a legitimação das diferentes áreas dos campos científicos e do "não científico". Rompendo, assim, com a lógica hierarquizante da racionalidade fundamentada no paradigma da ciência moderna, que segrega, marginaliza e verticaliza o conhecimento.

Com o desejo de mudança, pautado não pela justaposição e/ou pela eliminação, mas pela integração e transgressão - ir além dos limites fronteiriços - busca "[...] ecologizar conhecimentos científicos e saberes populares, religando dimensões do conhecer e do conhecido às multidimensionalidades do humano, da realidade e da vida" (SUANNO M., 2015, p. 69). Dessa forma, na epistemologia transdisciplinar, não há uma supremacia do conhecimento validado pelo cientificismo, mas a religação de conhecimentos e saberes diversos, originários tanto do campo da ciência como do âmbito das experiências do mundo vivencial, relacional, do senso comum.

Outrossim, mostra-se precípuo situar que a transdisciplinaridade, em uma vertente metodológica, promove a religação entre o sujeito e o objeto, pares dicotomizados no pensamento predominante do paradigma da simplificação (MORIN, 2002), situando-os como elementos acoplados e constitutivos da estrutura organizacional do conhecimento. Nesse escopo, encaminha-se para uma "[...] subjetividade objetiva do sujeito aprendente que se expressa de uma nova maneira" (MORAES, 2015a, p. 16), transcendente da lógica binária, fragmentada e excludente; apoiando-se, a partir de então, no princípio da complementaridade.

Face ao exposto, ressalta-se que, na abordagem transdisciplinar, ao invés da simplificação, são requeridos a interconexão e o convívio do diverso, partindo da compreensão de que os fenômenos apresentados estão interligados e constituem um todo em fluxo contínuo de trocas. Esse reconhecimento de "[...] pontes que religam as partes ao todo e unem as diferenças [...]" (MORAES, 2015a, p. 16) possibilita o olhar multidimensional dos elementos que compõem a realidade.

Nesse sentido, torna-se explícito que a inserção dessas bases interdisciplinaridade e transdisciplinaridade - na formação educacional se apresenta como uma nova perspectiva formativa, que se encaminha para uma visão do sujeito global, da valorização da diversidade, da ruptura com modelos que enclausuram o conhecimento. Dessa forma, possibilita-se um olhar que congrega e integra, vislumbrando a formação de sujeitos aptos a tomarem a realidade contextual, das instituições, da sua área de convivência e atuação, dos espaços nos quais se encontra inserido, de forma interconectada. 


\section{PRÁTICA E AÇÃO PEDAGÓGICA INTER/TRANSDISCIPLINARES: UM CAMINHO POSSÍVEL}

Para a melhor compreensão do sentido atribuído à ação e à prática pedagógica, as quais serão aqui apresentadas, convém um esclarecimento conceitual acerca de suas determinações, cuja distinção se faz necessária para os propósitos da presente reflexão.

Deste modo, no que se refere à busca por uma definição conceitual do termo ação, cabe a contribuição de Sacristán (1999, p. 30).

O termo ação é difuso e, por isso, a rigor impossível de definir, porque a ação só pode ser destacada ou descrita, pois tudo aquilo pelo qual poderia ser definida já contém em si o sentido de ser ação; qualquer verbo que utilizássemos para fazê-lo contém uma atividade - o definir já é uma ação.

Neste sentido, na tentativa de posicioná-la em uma referência que facilite a compreensão, arrisca-se em explicitar que ação pode ser entendida como atitude, atividade do sujeito, tomada de iniciativa, decisão, ato direcionado à realização de algo. A partir de então, pensada como ação pedagógica, neste trabalho, definir-se-á como atividade intencional do professor no espaço de sala de aula, cuja finalidade é o ato educativo, o que envolve posicionamentos, motivações e desejos do sujeito em um processo de intermediação constante com a prática e a estrutura institucional.

A ação assume uma posição central nos processos educacionais, pois conforme Sacristán (1999, p. 30),

[...] a educação em seu sentido mais genuíno, é ação de pessoas, entre pessoas e sobre pessoas. O que acontece no mundo educativo tem muito a ver com os agentes que dão vida, com suas ações, ás práticas sociais que contém nos sistemas educativos e em torno dos mesmos.

Situam-se, portanto, como atitudes projetadas e desencadeadas pelos sujeitos que perfazem o cenário educativo. Assim sendo, o conjunto dessas ações é a força motriz de uma dada realidade institucional que, somadas aos aspectos organizacionais, estruturais e às tendências sociais, caracterizam a especificidade de cada contexto educacional.

Nessa perspectiva, cabe destacar que a ação docente é singular, reflexo de simbologias, representações, fundamentos e experiências acumuladas por cada sujeito em seu processo de construção pessoal e profissional, assim, "o professor age como pessoa e suas ações profissionais o constituem” (SACRISTÁN, 1999, p. 31). A ação pedagógica, por conseguinte, é uma expressão da multidimensionalidade que constitui o eu, pessoa, aspecto esse, que referenda a diferença constitutiva dos agentes no seu fazer pedagógico.

De tal modo, faz-se pertinente destacar que a ação é individual, mas também se configura na relação com o outro; é projetada a partir das construções subjetivas, contudo, mantém relações recíprocas e se agrega ao campo das interações coletivas, da cultura intersubjetiva. 
Com essa compreensão, Sacristán (1999, p. 32) alude que:

Na educação, as ações são [...] reflexo da singularidade daqueles que a realizam
- levam seu selo -, se entrelaçam com outras ações em um emaranhado de
relações, constituem um estilo de ação próprio daqueles que se dedicam a
educar e obedecem um projeto coletivo que soma esforços próprios [...].

Sob essa ótica, constata-se que a ação é carregada de subjetividade, mas, também, de intencionalidade e de uma racionalidade objetiva que a conduz a objetivos e destinatários específicos, sendo que no caso das ações dos professores, os estudantes se constituem como estruturas receptivas e colaborativas. Com isso, fica estabelecido um projeto de formação consubstanciado pelo conjunto de ações derivadas dos agentes educacionais que compõem determinada realidade educativa e direcionadas ao cumprimento de objetivos compartilhados.

Por outro lado, no que se refere à tentativa de compreensão da prática pedagógica e buscando dissociá-la do sentido habitual que lhe é atribuído, como o fazer prático do professor em sala de aula, recorre-se à elucidação proposta por Sacristán (1999, p. 74, grifo nosso) a respeito do termo prática:

Embora, na linguagem coloquial, a palavra prática [...] seja utilizada para referir-se à realização da atividade, à técnica, em sentido amplo, distinguimos a atividade dos sujeitos [...] daquilo que é toda a bagagem cultural acerca da atividade educativa, que denominamos propriamente como prática ou cultura sobre a prática.

Assim, a partir dessa clarificação terminológica, pode-se entender a prática pedagógica como uma construção história que transcende, mas agrega, as ações dos sujeitos; que não é determinada somente como o fazer individual do professor no desenvolvimento de sua ação didática, mas que se refere à agregação de aspectos outros; é uma estrutura ampliada, uma cultura internalizada no espaço institucional. Situando-se, portanto, no campo da cultura historicamente consolidada, mas que pode ser enriquecida e redirecionada pela ação dos agentes.

Dessa forma, coadunando com a acepção de Sacristán (1999), Pinto (2011, p. 75 , grifo nosso) afirma que, "a prática pedagógica [...], não se refere apenas a uma ação individual, na verdade, trata-se de uma prática social situada, em que estão presentes as relações sociais que servem aos interesses humanos, sociais, culturais e, portanto, políticos, [...]". Com isso, infere-se que a prática pedagógica se efetiva como uma identidade institucional, construída historicamente e em relação direta com os sujeitos e o contexto social, consubstanciada pelo conjunto de ações, modos de ensinar e aprender, determinações, objetivos educacionais, arranjos sociais e estruturais de cada realidade, que, por assim se apresentar, identifica e diferencia a pluralidade das instituições.

A partir das elucidações sobre ação e prática, e com o intuito de sintetizar a tentativa de diferenciação entre ação e prática pedagógica, alude-se a contribuição contundente de Pimenta e Anastasiou (2002, p. 178, grifo das autoras), que a esse respeito afirmam: "a prática é institucionalizada, são as formas de educar que ocorrem em diferentes contextos institucionalizados, configurando a cultura e a 
tradição das instituições. Essa tradição seria o conteúdo e o método da educação". Por outro lado, a ação tem a ver com os "[...] sujeitos, seus modos de agir e pensar, seus valores, seus compromissos, suas opções, seus desejos e vontade, seu conhecimento, seus esquemas teóricos de leitura do mundo" (PIMENTA; ANASTASIOU, 2002, p. 178-179).

Pode-se afirmar, portanto, que enquanto a ação pedagógica concerne às atitudes dos sujeitos, a prática pedagógica amplia-se para um contexto macro, resultando em uma construção mais global que agrega outros elementos da realidade social e educacional, dentre eles o conjunto de ações que validam as posições dos agentes envolvidos.

Nas palavras de Sacristán (1999, p. 73, grifo nosso) essa distinção assim pode ser entendida:

A ação refere-se aos sujeitos, embora por extensão, possamos falar de ações coletivas, a prática é a cultura acumulada sobre as ações das quais aquela se nutre [...]. A prática é a cristalização coletiva da experiência histórica das ações, é o resultado da consolidação de padrões de ação sedimentados em tradições e formas visíveis de desenvolver a atividade.

Infere-se, pois, que ação e prática se retroalimentam no espaço institucional, uma interferindo na composição configuradora da outra, haja vista que ambas são interdependentes, suas dinâmicas estão imbricadas e se afetam mutuamente. Assim, depreende-se que o fazer docente é consolidado por meio da ação dos professores, mas se relaciona com a prática historicamente institucionalizada.

Diante dessa incursão inicial, imprescindível para as discussões posteriores, buscar-se-á apresentar algumas características da ação e da prática pedagógica, amparadas nos fundamentos da interdisciplinaridade e da transdisciplinaridade.

Com essa perspectiva, destaca-se que as reflexões da prática pedagógica referenciada nos fundamentos epistemo-metodológicos da interdisciplinaridade e da transdisciplinaridade propõem o questionamento e o redirecionamento da cultura educacional que se comporta pelo olhar da fragmentação, da disjunção, de modelos operacionais baseados na racionalidade técnica, buscando situar um novo eixo orientador, o qual se firma na proposição de "[...] uma prática pedagógica que supere a fragmentação e a reprodução do conhecimento" (BEHRENS, 2011, p. $55)$.

Destarte, o desejo de superação da influência do paradigma da simplificação, que tem caracterizado a prática pedagógica, enseja a necessária busca por alternativas que fundamentem "[...] uma prática pedagógica mais dinâmica e eficiente, que integre alunos, professores, disciplinas, cursos [...]" (JOSGRILBERT; SUANNO J., 2015, p. 111). Para tanto, é requerida a ascendência de novas atitudes e ações que congreguem para a efetivação de outras experiências, que, situadas em um tempo e espaço históricos, possam exercer mudanças na prática configuradora das instituições formativas. 
Sob essa ótica, a interdisciplinaridade, como orientadora de mudanças no âmbito educacional, é promotora de um projeto cujo objetivo é a religação, a cooperação e a complementaridade, em que a "[...] separação entre as ciências é substituída pela convergência a objetivos comuns" (FAZENDA, 2003, p. 43), inserindo, com isso, a necessidade de um diálogo ampliado, que reconheça a importância de um trabalho coletivo, cooperado, de um envolvimento recíproco, e que, por ser perpassado pela diversidade de olhares, se constitui como processo enriquecido e enriquecedor para os sujeitos atuantes.

Assim, o desenvolvimento do trabalho educacional, que consequentemente envolve ação e prática pedagógica, guiado por um viés interdisciplinar, consiste em uma tentativa recorrente e intencional de firmar novas e ampliadas parcerias, partindo da solidariedade, da humildade e da abertura para com o outro. Isso porque a interdisciplinaridade vai além de uma simples troca entre especialistas, pois, para sua efetivação, torna-se necessária a parceria no planejamento, na articulação dos diferentes conteúdos, no compartilhar de estratégias, métodos e metodologias, em um movimento de influência contínua e recíproca com vistas à superação de um território excessivamente privado e isolacionista na ação docente.

De tal modo, como embasamento epistêmico, possibilita a produção de novos saberes, teóricos, didáticos, pedagógicos, ao mesmo tempo em que contribui para a manifestação das subjetividades, ao potencializar a construção de pontes entre os sujeitos, subsidiada pela busca recorrente de parcerias e da assunção da coletividade.

Dessa maneira, a ação e a prática pedagógica pensadas sob a égide interdisciplinar têm, por centralidade, o estabelecimento da comunicação entre as diferentes vertentes disciplinares, podendo direcionar, segundo Anjos (2015, p. 36), para uma "[...] concepção crítico-reflexiva, calcada no pensamento mais integral e conecto [...] na articulação entre teoria e prática, na participação ativa dos sujeitos em seu processo de formação e na problematização e intervenção da realidade [...]", visto que possibilita a ampliação acerca dos fenômenos ao intercruzar olhares, promovendo, assim, uma abertura de horizonte e um aprofundamento analítico.

Nesse mesmo direcionamento, a fundamentação desse ideal de prática tem respaldo na transdisciplinaridade, uma vez que, de acordo com Behrens (2015, p. 43),

Inúmeras são as implicações da transdisciplinaridade na prática pedagógica, pois, sendo ela orientadora do pensamento e da ação, permite que a docência amplie a capacidade de reflexão [...], de trocas, de interações e conexões, organizando ambientes flexíveis, dinâmicos, imprevisíveis e criativos.

Sendo assim, com essa influência direta na docência e em todos os aspectos que constituem o ambiente de formação, a transdisciplinaridade provoca o reordenamento de atitudes, promovendo uma abertura, um olhar sensível, catalisador das diferenças como via de ressignificação e construção permanente do cenário formativo. É o despertar de uma consciência que incide em uma (re)construção contínua da prática social caracterizadora de cada instituição, contribuindo para a 
reorganização do estabelecido e na criação de novas formas de atuação, tendo em vista o contexto mutável da sociedade em todas as suas dimensões.

Assim, projeta-se a configuração de uma cultura institucional que, estando ligada ao meio social, promova a formação de sujeitos éticos, democráticos, autênticos, que sejam capazes de intervir de modo autônomo na consolidação de mudanças. Logo, urge a necessidade de um projeto de formação que não se direcione à simples transmissão de técnicas para a transposição de conteúdos, como tem sido configurado o modelo formativo apregoado pela racionalidade técnica, mas de uma formação emancipadora que prepare sujeitos aptos à participação ativa no contexto da coletividade.

Dessa maneira, para a institucionalização de novas práticas, é fundamental a consolidação de uma cultura identitária nas instituições formativas, que tenha por características a partilha, a comunhão, o trabalho coletivo, a integração disciplinar e a conjunção dos esforços por meio do desenvolvimento de parcerias significativas, incidindo "[...] em uma prática pedagógica crítica, produtiva, reflexiva e transformadora" (BEHRENS, 2011, p. 66).

Sob essa ótica, vislumbra-se o desenvolvimento de ações docentes fundamentadas a partir de uma visão sistêmica que visualize os fenômenos e os atores educacionais como interdependentes, encaminhando uma ação pedagógica na qual seja possível "[...] estabelecer relações dialógicas nas quais possam realizar um trabalho coletivo, participativo, criativo, transformador [...]" (BEHRENS, 2011, p. 68). Nesse aspecto, é possível referenciar como características organizadoras das relações intersubjetivas no espaço educativo compartilhado: a abertura ao outro e aos posicionamentos plurais, bem como a tolerância ao diferente.

Para tanto, a supressão das dicotomias é um fator a ser contemplado, visto que a lógica inter-transdisciplinar nas vivências educacionais rompe com as polaridades que concebem um caráter unidimensional e excludente aos processos educativos.

Com isso, professores e estudantes, protagonistas do processo de ensino e aprendizagem que foram separados e referenciados como figuras isoladas, são reintegrados como sujeitos partícipes do processo, ambos ensinando e aprendendo. $\mathrm{E}$ assim, "consequentemente, docente e discente evoluem juntos, revelando que [...] o saber docente também evolui em comunhão com o saber e o sabor experiencial discente, vivenciando uma relação de interdependência docente/discente" (MORAES, 2007, p. 34).

Destarte, é concebida uma construção compartilhada, cuja base de sustentação se dá no diálogo, na reciprocidade e na tentativa recorrente de constituição e reconstrução dos componentes envolvidos no ato formativo, culminando em um aprendizado permanente, em que professores e estudantes se informam e se transformam mutuamente.

Por conseguinte, a visão do professor em relação ao estudante não é a de que ele é um recipiente vazio que necessita passivamente assimilar conhecimentos, tampouco à diversidade em sala de aula é enquadrada em padrões homogeneizantes, 
mas, antes, recorre-se a um fundamento que caracteriza o estudante " $[. .$.$] como um$ ser complexo que vive num mundo de relações e que, por isto, vive coletivamente, mas é único, competente e valioso" (BEHRENS, 2011, p. 65). Logo, é um sujeito que se faz na relação com o outro, mas é autônomo e dotado de potencial para atuar reflexivamente na sua construção pessoal e profissional. Para além disso, nas palavras de Moraes (2015b, p. 63), o estudante é "um sujeito multidimensional, com todas as suas estruturas perceptivas e lógicas, como também sociais e culturais à disposição de seu processo de construção do conhecimento [...]", que é contínuo e recorrente.

Nessa perspectiva, a efetivação de uma cultura de compartilhamento na atuação pedagógica só é possível a partir do empreendimento de uma relação horizontal, dialógica,

[...] valorizando a construção coletiva do conhecimento, a criação de cenários participativos, a descentralização dos processos, priorizando a alteridade e reconhecendo o outro em seu legítimo outro [...] O diálogo é uma exigência existencial e implica uma relação horizontal e não vertical entre as pessoas. E é nesse diálogo conjunto que se produz e se valoriza o saber coletivo (MORAES, 2015b, p. 103).

Dessa forma, o fazer pedagógico, a partir dos fundamentos da interdisciplinaridade e da transdisciplinaridade, se consolida na aceitação de um processo de ensino e aprendizagem construído coletivamente, firmado por meio de cooperação, integração e valorização das diversidades.

Assim sendo, emerge a lógica que inclui a pluralidade de representações, partindo da validação de posicionamentos e dinâmicas plurais, heterogêneas e múltiplas. Lógica presente em cada sujeito, que carrega em si um mundo de variedade e de concepções vivenciais. A partir disso, projeta-se uma ação docente [...] dialógica, complexa, sensível, integradora, criativa ao se trabalhar reconhecendo os distintos níveis de realidade e de percepção dos alunos (MORAES, 2015b, p. 105).

Outra característica que se faz imprescindível para o desenvolvimento de uma ação docente pautada nesses referenciais inclina-se à busca pela religação entre os diferentes campos disciplinares. Essa integração, promovida por meio da interdisciplinaridade, conduz ao rompimento do caráter unidisciplinar, possibilitando, no processo de formação, a conexão entre os distintos saberes curriculares.

Para tanto, desvela-se a necessidade do desenvolvimento de parcerias entre os docentes, e a consolidação de intersubjetividades, os quais conscientes de que cada disciplina é apenas uma parcela do conhecimento, promovam ações compartilhadas "[...] calcadas no diálogo e no trabalho coletivo [...]" (BEHRENS, 2011, p. 76). O que desencadeia um intercruzamento de dimensões subjetivas e áreas disciplinares, ocasionando o estabelecimento dos laços entre as distintas áreas do saber.

De igual modo, recorre-se à valorização de saberes plurais, originários de outros contextos, para além daqueles institucionalizados no currículo. Esses saberes 
conferem, à ação do professor, uma abertura que diversifica e enriquece o processo formativo, dando sentido e visibilidade ao que o estudante vivencia no contexto das relações sociais que transcendem os muros da universidade.

A lógica inter-transdisciplinar na ação pedagógica encaminha, também, para a importância da contextualização do que é vivido no interior da sala de aula, por meio do qual é possível demonstrar a interconectividade dos fenômenos em escalas local e global, e, ainda, acrescentar significado e sentido ao que é aprendido, uma vez que, segundo Moraes (2010), citada por Suanno, J., Paula e Arantes (2015), nada tem sentido sem o contexto.

Acrescenta-se, ainda, à ação pedagógica alicerçada nos fundamentos da interdisciplinaridade e da transdisciplinaridade, o desenvolvimento de metodologias com uma "[...] dimensão inclusiva, construtiva e criativa [...]" (MORAES, 2007, p. 29), que incitem os estudantes à busca e ao desejo por aprender, participar, a serem colaboradores do processo de ensino e aprendizagem.

Assim, vislumbra-se a emergência de metodologias dinâmicas, plurais, criativas, que reorganizem os modos rotineiros de ensinar e aprender em sala de aula, que busquem a motivação, despertando a curiosidade. Por conseguinte, o desenvolvimento de:

[...] estratégias baseadas na aprendizagem relevante, no desenvolvimento de habilidades cognitivas, numa atitude transformadora; na organização de atividades inovadoras, flexíveis, motivadoras; numa intervenção que tenha em consideração a experiência, a colaboração, o envolvimento do aluno (TORRE, 2002, p. 103).

Busca-se, assim, potencializar a interação em sala de aula, rompendo com formas de ensinar e aprender que se sustentam unicamente na exposição em forma de monólogo, circunscritas no caráter transmissivo, que, em vez de situar os diferentes sujeitos como colaboradores na construção do seu próprio conhecimento, os referenciam apenas como expectadores e receptores de conteúdo.

Nessa mesma direção, o ensino com pesquisa se apresenta como um pilar indissociável no contexto da ação do professor no desenvolvimento do seu trabalho pedagógico. Com isso, vislumbra-se que docentes e discentes, conjuntamente, sejam promotores de "metodologias de busca e de construção de conhecimentos (ensinar com pesquisa); que confronte os conhecimentos elaborados e as pesquisas com a realidade; mobilize visões inter e transdisciplinares sobre os fenômenos [...]" (PIMENTA; ALMEIDA, 2009, p. 17). E, a partir desse entendimento, se constituam como produtores de conhecimento na realidade educacional e social, na qual estão inseridos.

Tendo essas bases - interdisciplinaridade e transdisciplinaridade - como fundamento, alicerçadas na complexidade, é possível pontuar a assunção de ações pedagógicas com características criativas. Nesse sentido, Suanno, M. (2010a; 2010b) contribui ao apresentar alguns aspectos constitutivos de atitudes pedagógicas de caráter criativo, inovador e emancipador: 
- compreender a autonomia, criticidade e criatividade como atitudes interdependentes;

- perceber as relações entre pensamento e emoção;

- desenvolver a escuta sensível;

- promover a escuta musical em cenários de aprendizagem;

- utilizar em sala de aula perguntas mediadoras e favorecer a elaboração de sínteses provisórias;

- educar por projetos de trabalho, por projetos de investigação;

- considerar os conhecimentos prévios dos acadêmicos no processo de ensino e de aprendizagem;

- promover aprendizagem cooperativa.

Considerando o exposto, depreende-se que as características de uma ação docente, guiada pelos fundamentos da interdisciplinaridade e da transdisciplinaridade, se enriquece por não se fazer sozinha. Nela, a partilha, a parceria, a integração disciplinar e a busca pelo aprendizado construído coletivamente constituem o cerne das atitudes individuais e coletivas, que se desdobram no fortalecimento do processo de ensino e aprendizagem.

\section{CONSIDERAÇÓES FINAIS}

A interdisciplinaridade e a transdisciplinaridade são estabelecidas como abordagens que visam à religação, à articulação e à valorização do que é diverso e emergem como valores essenciais em um contexto questionador dos axiomas erigidos pelo paradigma firmado na modernidade. Paradigma este que apresenta, na contemporaneidade, um esgotamento quanto ao potencial de explicação do ser humano, do cosmo e do conhecimento.

Assim, encaminhar a ação pedagógica na perspectiva dessas bases epistemometodológicas apresenta-se como uma alternativa para se pontuar processos menos desarticulados, unidirecionais e firmados para além da racionalidade técnica que prioriza a transmissão, a acumulação, a reprodução e a assimilação passiva de conteúdos. Preconiza-se um movimento de abertura, de dialogicidade, de envolvimento que não refuta o emocional e valoriza a diversidade de sujeitos e saberes.

Com essa premissa, e, a partir dos referenciais estudados, alude-se a algumas possibilidades e perspectivas para a consecução da formação, no âmbito educacional, sob o olhar da interdisciplinaridade e da transdisciplinaridade, dentre as quais, cabe ressaltar as seguintes: requer uma postura de mudança que deve emanar dos sujeitos: consciência, ações e atitudes amparadas pela visão de integração, valorização e complementaridade; uma visão multidimensional na formação que engloba o sujeito em sua inteireza; abordagem sistêmica que valida e interconecta todos os agentes e elementos constituintes do processo formativo; um novo paradigma epistemológico que direcione mudanças na lógica que fundamenta 
a construção do currículo e das ações pedagógicas; relativização da lógica da racionalidade técnica e a assunção da complexidade como base de pensamento e ação; desenvolvimento de processos coletivos e de projetos pedagógicos reflexivos e alicerçados em parcerias.

No que diz respeito à ação pedagógica, algumas características podem ser pontuadas, dentre as quais: mudança na relação hierárquica entre professor e estudante, pautando essa relação no diálogo e na escuta sensível; relativização na lógica de transferência do conhecimento - o estudante com suas construções prévias é visto como agente de sua aprendizagem; aula como elemento construído conjuntamente - professor e estudantes; inserção e valorização de saberes que estão para além dos conhecimentos acadêmicos; promoção de um conhecimento contextualizado com a realidade local; estratégias didáticas que permitam a participação ativa dos discentes.

Assim sendo, a partir das considerações tecidas, cabe ressaltar que o desenvolvimento da ação pedagógica, tendo por alicerce a interdisciplinaridade e a transdisciplinaridade, se sustenta em um movimento de atitude frente à constatação da insuficiência dos modelos que têm configurado o contexto educacional e das exigências da contemporaneidade, que requerem uma visão ampliada sobre os processos que envolvem as múltiplas dimensões da vida humana.

\section{REFERÊNCIAS}

AIUB, Mônica. Interdisciplinaridade: da origem a atualidade. O Mundo da saúde. São Paulo, 2006, jan/mar 30 (1): 107 - 116. Disponível em: http://www.saocamilo-sp.br/pdf/ mundo_saude/34/interdisciplinaridade.pdf . Acesso em: 12 set. 2016.

ANJOS, Maylta Brandão dos. Interdisciplinaridade na condução docente: impressões a partir da vivência. In: PINHO, Maria José de; SUANNO, Marilza Vanessa Rosa; SUANNO, João Henrique; FERRAZ, Elzimar Pereira Nascimento (orgs.). Complexidade, Interdisciplinaridade e Transdisciplinaridade na educação superior. Goiânia: Espaço acadêmico, 2015.

BEHRENS, Marilda Aparecida. Contributos de Edgar Morin e Paulo Freire no paradigma da complexidade. In: BEHRENS, Marilda Aparecida; ENS, Romilda Teodora. Complexidade e transdisciplinaridade - novas perspectivas teóricas e práticas para a formação de professores. Curitiba, APRRIS, 2015. vozes, 2011.

. O paradigma emergente e a prática pedagógica. 5 ed. Petrópolis, RJ:

FAZENDA, Ivani Catarina. Interdisciplinaridade: qual o sentido? São Paulo: Paulus, 2003.

GADOTTI, Moacir. Interdisciplinaridade - atitude e método. 1999. Disponível em: http://www.paulofreire.org/moacir_gadotti/artigos/portugues/filosofia_da_educaçao. Acesso em: 09 set. 2016. 
JOSGRILBERT, Maria de Fátima; SUANNO, João Henrique. Uma experiência transdisciplinar no ensino superior. In: PINHO, Maria José de; SUANNO, Marilza Vanessa Rosa; SUANNO, João Henrique; FERRAZ, Elzimar Pereira Nascimento (orgs.). Complexidade, interdisciplinaridade e transdisciplinaridade na educação superior. Goiânia: Espaço acadêmico, 2015.

MORAES, Maria Cândida. O paradigma educacional emergente. 16 ed. Campinas, SP: Papirus, 1997.

. Da ontologia e epistemologia complexa à metodologia transdisciplinar. Revista Terceiro Incluído, Goiânia, GO, v.5, n.1, p. 1-19, jan./jun., 2015a. Dossiê ECOTRANSD: Ecologia dos saberes e Transdisciplinaridade. Disponível em: http:// www.revistas.ufg.br/index.php/teri/issue/view/1593/showToc. Acesso em: 15 ago. 2016.

. Transdisciplinaridade, criatividade e educação: Fundamentos ontológicos e epistemológicos. Colaboração de Juan Miguel Batalloso Navas. Coleção Práxis. Campinas, SP: Papirus, 2015b.

. A formação do educador a partir da complexidade e da transdisciplinaridade. Diálogo educacional, Curitiba, v. 7, n. 22, p. 13-38, set./dez. 2007.

MORIN, Edgar. Introdução ao pensamento complexo. Tradução de Eliane Lisboa. 3 ed. Porto Alegre: Sulina, 2007.

. Os sete saberes necessários à educação do futuro. Tradução de Catarina

Eleonora F. da Silva e Jeane Sawaya. 6 ed. São Paulo: Cortez; Brasililia, DF: UNESCO, 2002.

NICOLESCU, Basarab. O Manifesto da transdisciplinaridade. Tradução de Lucia Pereira de Souza. São Paulo: TRIOM, 1999.

PEREIRA, Fabíola Andrade; PINHO, Maria José de Pinho. Política de formação docente do curso de Pedagogia- PARFOR: construindo novas possibilidades. In: NETO; Armindo Quillici Neto; SILVA, Fernanda Duarte Araújo; SOUZA, Vilma Aparecida (orgs.). Formação de professores: perspectivas e contradições. Uberlândia: Composer, 2015.

PIMENTA, Selma Garrido; ANASTASIOU, Léa das Graças Camargos. Docência no ensino superior. São Paulo: Cortez, 2002.

PIMENTA, Selma Garrido; ALMEIDA, Maria Isabel de (Orgs.). Pedagogia universitária. São Paulo: Edusp, 2009.

PINTO, Ivone Maciel. Docência inovadora na Universidade. 2011. 368 fls. Tese (Doutorado em Educação) - Universidade Federal de Goiás, Goiânia, 2011.

SACRISTÁN, José Gimeno. Poderes instáveis em Educação. Porto Alegre, RS: Artes Médicas Sul, 1999.

SANTOS, Akiko et al. Ensino Integrado: Justaposição ou Articulação? In: SANTOS, Akiko; SOMMERMAN, Américo. Ensino disciplinar e transdisciplinar: uma coexistência necessária. Rio de Janeiro: WAK, 2014. 
SANTOS, Boaventura de Sousa. Um discurso sobre as ciências. $12^{\mathrm{a}}$ ed. Porto: Afrontamentos, 2001.

SOMMERMAN, Américo. Inter ou transdiciplinaridade? Da fragmentação disciplinar ao novo diálogo entre os saberes. São Paulo: Paulus, 2006.

SUANNO, Marilza Vanessa Rosa. Didática e trabalho docente sob a ótica do pensamento complexo e da transdisciplinaridade. 2015. $493 \mathrm{fls}$. Tese de Doutorado em Educação. Universidade Católica de Brasília - UCB, Brasília, 2015.

UNIVERSIDADE E PRÁTICAS PEDAGÓGICAS INOVADORAS. In: II

Forum Internacional y V Jornadas sobre Innovación y Creatividad - Una mirada Transdisciplinar y ecoformadora. Barcelona, 10 al 12 de junio de 2010a. Disponível em: http://www.ub.edu/doe/activitats/documents/TripticoForumCa\%20BCN2010.pdf. Acesso em: 14 ago. 2017.

. Inovação pedagógica no contexto universitário. In: II Forum

Internacional y V Jornadas sobre Innovación y Creatividad - Una mirada

Transdisciplinar y ecoformadora. Barcelona, 10 al 12 de junio de 2010b. Disponível em: http://www.ub.edu/doe/activitats/documents/TripticoForumCa\%20BCN2010.pdf. Acesso em: 14 ago. 2017.

SUANNO, João Henrique; PAULA, Marcos Vinícius Guimarães de; ARANTES, Victor Hugo de Paiva. O olhar transdisciplinar para a educação física escolar. In: PINHO, Maria José de; SUANNO, Marilza Vanessa Rosa; SUANNO, João Henrique (Orgs.). Projetos criativos na prática pedagógica: cantar e encantar a aprendizagem. Goiânia: Espaço acadêmico, 2015.

TORRE, Saturnino de La; Estratégias didáticas inovadoras e criativas. In: TORRE, Saturnino de La; BARRIOS, Oscar (orgs). Curso de formação para educadores. São Paulo: Madras Editora Ltda, 2002.

TRONCA, Sanvitto Dinorah. Transdisciplinaridade em Edgar Morin. Caxias do Sul, RS: Educs, 2006. 